\title{
Virtual Project Management Of Globally Outsourced IT Projects
}

\author{
Mahesh Raisinghani, Texas Woman's University, USA \\ Anshu Arora, Savannah State University, USA \\ Erice Baylor \\ Shelley Brown-Philips \\ Ceriese Coleman \\ Kelvin Craig
}

\begin{abstract}
The existing literature on how globally outsourced information technology (IT) projects are reliant on technology for virtual project management was extended by presenting a new framework for virtual project management and analyzing the current internet-based collaborative tools that facilitate their effectiveness. This assertion derives from an effort to answer the following research question: How are globally outsourced IT projects reliant on technology for virtual project management?
\end{abstract}

Keywords: Project Life Cycle, Virtual Project Management, Global Outsourcing, Computer-Mediated Support, Knowledge Management

\section{INTRODUCTION}

hile there is significant information on managing globally outsourced IT projects reliant on
technology, there is currently minimal data on integrative project management, establishing team
trust, knowledge management and shared understanding, and decision-making. This problem exists because the available literature on globally outsourced IT projects has not kept pace with the rapidly changing and expanding discipline of virtual project management. The field of virtual project management is not likely to see a decline in the coming years. In addition, it is likely that today's global marketplace coupled with the increased costs of travel, tight schedules, and high expectations for project deliverables, will support an explosion of global virtual project management. Growth and expansion of virtual project management necessitates devoting more measurable information to the discipline.

The following paper reviews the literature available on globally outsourced IT projects and acknowledges that no new research studies were undertaken during this endeavor. The approach examines a variety of existing literature in management, science and software development disciplines to retrieve information on virtual project management as it relies on technology in the global environment. There is discussion on the research findings followed by examination of the limitations and implications for research and the implications for management. The discourse continues with key takeaways for management, lessons learned and a final conclusion.

\section{LITERATURE REVIEW \& SYNTHESIS}

There were several concepts that emerged from the review of a variety of existing literature in management, science and software development disciplines as they relate to globally outsourced IT projects. For instance Chakrabarty (2007), Qureshi (2006) and Brooks (2006) present concepts regarding boundary challenges temporal, cultural, organizational and geographical. Similarly, Gray and Larson (2008) present the concept of an integrative approach to project management. Thus, the following review examines and presents information on virtual project management as it relies on technology in the global environment, and presents concepts for effective project management and current internet-based collaborative tools that facilitate their effectiveness. 


\section{Effective Project Management}

Most information technology projects are fraught with problems and risk. A significant amount of these projects fail to materialize or bring about the full set of objectives they set out to deliver. Nearly all IT projects even while employing effective project management practices are affected by inherent risks and problems that arise in areas such as time, resources, scope and/or quality. Researchers such as Tiwana and Kiel (2004) in a survey of managers of information systems presented six factors that contributed to risk and problems for IT projects. These are: inappropriate methodology use, lack of customer involvement, lack of formal management practices, uniqueness of the project, project complexity and volatility of requirements (Tiwana \& Kiel, 2004, p. 74). These factors held true for traditional as well as globally outsourced IT projects.

Under a traditional project environment where projects are undertaken with teams co-located while working together, effective project management would encompass a capacity to utilize a powerful set of tools and techniques that improves the ability to plan, implement and manage activities to accomplish specific organizational objectives (Gray and Larson 2007, p. 3). These goals are the same for effectively managing globally outsourced IT projects reliant on technology for virtual project management. However, successful project management in a virtual environment proves even more challenging. Project managers working in a virtual environment not only have to employ tools and techniques that improves their ability to plan, implement and manage project activities, they also have to implement systems that control the operating environment by creating boundaries for performance in the virtual realm.

Most research on virtual project management of outsourced IT projects points to utilizing an integrative approach to project management that aligns project objectives with the strategic objectives of the managing organization. As Gray and Larson (2008) stress, "an increasing percentage of typical firms' effort is being devoted to projects" (p. 10). Furthermore, as Gray and Larson (2008) state "the future promises an increase in the importance and role of projects in contributing to the strategic direction of organizations" (p. 10). Moreover, as Gray and Larson (2008) point out "effective project management begins with selecting and prioritizing projects that support the firm's mission and strategy" (p. 15). The globally outsourced project manager by understanding the vision and objectives of the organization affords them the ability to manage the project with respect to the organizations involved. Furthermore, as Beranek (2006) in a graduate thesis on global virtual project management found, research encourages an "understanding the relationship between the organization's business strategies and how projects affect those strategies" as well as "understanding these relationships require understanding the spectrum of strategic problems" as necessities in global project management success (p. 77).

In addition, the research literature established the types of business influential and practical factors that were shown to have a relationship with virtual project management and its success and/or failure. The business influential factors of virtual project management were organization vision and goals, sponsor support, customer interviews and involvement, project leader coaching and mentoring, project team development and competency, startup workshops or kickoff meetings, organization culture, communications planning, decision-making, and creative problem-solving (Beranek 2006, p. 94). Practical factors for virtual project management include contract administration, project planning and documentation, cost estimation and budgeting, plan optimization and scheduling, constraint management, multiple dependent projects coordination, progress monitoring, project and contract closeout, secure and reliable technical infrastructure and collaboration tools (Beranek 2006, p. 95). By understanding the precise business influential and practical factors that contribute to successfully managing globally outsourced IT projects, project managers with the organization goals in mind can establish and implement a framework approach to virtual project management with the understanding that each globally outsourced IT project undertaken will not be one size fits all. This integrative framework helps the managing organization and the other entities involved assess and enhance their internal control systems, incorporating policies, rules and regulations on outsourced IT project management. Equally as important, this permits organizations to better control their activities while moving toward achievement of their established goals and enhance abilities to manage project risk. Furthermore, this can present an organization with tangible rewards in the future for handling tasks, resources and tracking activities of globally outsourced IT projects aligned with the business' objectives. 
Virtual project management of globally outsourced IT projects necessitates the utilization of the same talents as traditional project management. In a study on critical risks in outsourced IT projects, Taylor (2006) examined the vendors' perspective and found two key risks that were difficult to manage and thus important to all project stakeholders. These were "overoptimistic schedules and budgets and inflated client expectations" which the research claimed stemmed from "the vender's desire to win business in a highly competitive marketplace" (Taylor 2006, p. 76). The uniqueness of project work, especially globally outsourced IT projects require an approach that is centered on systems infrastructure, management control and performance measurement.

One approach of traditional project management suggests utilizing the project life-cycle as the foundation of successful project management. Utilizing this approach can assist project managers overcome poor planning which has habitually doomed highly uncertain projects like globally outsourced IT projects. As Gray and Larson (2008) emphasize "the project life cycle typically passes sequentially through four stages: defining, planning, executing, and delivering" (p. 7). Every possible element of a project takes place throughout these four stages. In addition, the four stages of the project life cycle have a beginning and an end. It is unlike Gantt charts and project networks in that they represent significant changes as the project advances through subsequent stages of maturity. The changes are progressive levels of detail in management decision-making, type and flexibility of management style, and the skill sets required by project managers. Furthermore, points of control comprised of major milestones at which specific deliverables are expected, set apart these high-level strategic stages. These control points make certain that project progress moving beyond them is acceptable because of successful completion of a carefully scrutinized and satisfactory deliverable. Accordingly, controlling events utilizing traditional project management techniques such as utilizing the project life cycle as the cornerstone can ensure identification of project risks before they occur. Additionally, effective virtual project management of globally outsource IT projects with the project life cycle as the cornerstone of project management gives the project manager and the contracting firm the defined metrics, benchmarks, disincentives and incentives by which performance will be measured.

Lastly, projects that are undertaken through global outsourcing provide great opportunities for increased communication. However, in spite of its advantages, it increases risk for managing projects especially in terms of time, resources, scope, and quality. Project managers have to take advantage of and master project management and web-based collaborative tools for virtual project management in order to work, share and measure performance in the virtual environment. This allows the project manager to foster an environment that allows team members to work together while apart and simultaneously - control, coordinate and work towards the desired end result. Project managers should lay out tasks, assign resources and track performance utilizing project management software and other collaborative tools. Table 1 on global project management computer-mediated support demonstrates aspects of project management and the types of tools available for project managers of globally outsourced IT projects to utilize to ensure project performance (PMI, 2004). With this approach, the project manager can adhere to the planned agenda of keeping the project on target. The effective project management of a virtual project significantly relies on the ability to manage limitations in the virtual realm. Thus, employing an integrative approach along with traditional project management tools and techniques that are centered on the project life-cycle provide the framework for managing a globally outsourced IT projects.

\section{KNOWLEDGE MANAGEMENT}

As advances in information technology (IT) have fueled the ability to globally outsource technology projects, the expected benefits of doing so have reciprocally increased the demand to improve the technology utilized for engaging in such endeavors (Brooks, 2006; Qureshi, 2006). Companies pursuing selective or total global IT project outsourcing expect to realize benefits including lower costs and cost-effectiveness; access to increased technical expertise, technology, and creativity; competitive advantage; business value; rapid delivery and increased productivity, and increased quality (Chen, 1998; Kliem, 2004; Murray, 2006; Qureshi, 2006).

The efficacy and feasibility associated with globally outsourcing IT projects, given the temporal, cultural, organizational and geographical boundary challenges, would be diminished if not for the facilities offered by collaborative technologies (Chakrabarty, 2007; Qureshi, 2006; Brooks, 2006). Technological advancements in and utilization of global networks and internet-based technologies have decreased the overhead costs associated with effective global coordination (Xu, 2007). According to Chakrabarty (2007), advancements in conferencing 
technologies have allowed virtual project teams to "effectively interact, share and manage project related information" (p. 1). While some researchers purport that groupware can enable virtual project teams the same success in sharing information, making decisions, and completing tasks as collocated project teams (Schermerhorn, 2005; Thomas, 2007), it was also found that virtualization may nonetheless cause teams to experience conflict resolution difficulties, protracted team building, or schedule delays associated with constraints in communication channel richness (Lu, 2006; Workman, 2007). Furthermore, a reliance on too many information and communication technologies (ICTs) given the aforementioned boundaries can also present barriers to achievement of project objectives (Brooks, 2006; Thomas, 2007). When teams used a median of 12.5 ICTs, the sheer number, differences and interfaces between the ICTs spawned interaction opportunities (Thomas, 2007). As such, project teams functioning in global, virtual project environments should seek to align the appropriate technology with the right task (Engleberg, 2007; Hambley, 2007; Thomas, 2007). While there are demonstrable usages in which technology facilitates virtual project management in globally, outsourced IT environments, the focus of this paper is on trust, knowledge management and shared understanding, and decision-making.

\section{Trust}

Although the criticality assessment results were not unequivocal, the research consensus is that establishing trust within any organizational structure inclusive of virtual project teams is a key to success, and that trust is fundamentally established via communication (Bouley, 2006; Brooks, 2006; Cusick, 2006; Lu, 2006). In a global, outsourced virtual project environment trust is predominantly facilitated by formal and informal electronic communication channels, e.g., Tele-, Audio-, Data-, Video-conferencing (Brooks, 2006; Hambley, 2007). Although ICTs greatly support communication in complex virtual environments, face-to-face interaction, even if only during the initial project kickoff, was also postulated to be irreplaceable for building trust within the virtual project team (Bouley, 2006; Hambley, 2007; Lu, 2006). Risks associated with establishing team trust in globally, outsourced virtual project environments is most effectively mitigated via a two-pronged approach; leveraging collaborative technologies and face-to-face interactions.

\section{Knowledge Management/Shared Understanding}

In addition to establishing trust within the global project team, shared understanding is a critical element for virtual project success. Researchers have found that collaborative technologies (e.g., The Internet, The World Wide Web, Web Services, global digital networks, integrated development environment, virtual prototyping) combined with groupware can facilitate knowledge management and the sharing of information that leads to shared understanding within global project teams (Brooks, 2006; Ranganathan, 2007 Qureshi, 2006). While there are different models for successful knowledge management, the models concur that the use of technology to enable knowledge management is a core component (Haddad, 2007). Knowledge management processes related to outsourcing include the creation, retention, transfer, and exploitation of tacit technical and business knowledge between the outsourcer and supplier (Haddad, 2007; Ranganathan, 2007). Thomas (2007), found that geographically dispersed project teams have utilized computer facilitated capabilities that enable knowledge transfer and shared understanding such as visibility and accessibility to shared information repositories, co-ability to manipulate information, and virtual exchangeability.

In spite of the availability and effectiveness of knowledge management and information sharing technologies, potential knowledge seepage and team misunderstandings can be further mitigated by physically bringing key onsite and offshore resources together at various points during the transition (start up and closeout) and execution phases of virtual projects (Cusick, 2006; Murray, 2006;Ranganathan, 2007). Risks associated with effectively managing knowledge and ensuring shared understanding in globally, outsourced virtual project environments are most successfully mitigated via an integrated framework that is appreciative of the dynamism of the people, efficiency of the processes utilized, and the value-add of the technology that supports the model.

\section{Decision-Making}

Decision-making involves reviewing issues and making choices between alternatives (Engleberg, 2007). Trust, knowledge management, and shared understanding are antecedents to effective decision-making (Christian, 2002; Qureshi, 2006). Examples of decisions project teams make consist of how to utilize resources and when a 
product is ready to launch. Effectual and expeditious decision-making is vital to all types of project structures, the quality of which has a direct and significant impact on the success ability of the initiative. The availability of prerequisite information along with its accuracy and completeness are, for the most part, matters related to knowledge management and shared understanding (Haddad, 2007). The ability to make prudent, rapid decisions within the context of globally dispersed project teams is also dependent upon the use of group decision support tools and groupware (e.g. videoconferencing) to improve decision-making (Engleberg, 2007; Qureshi, 2006). On the one hand, while computer-mediated decision-making allows the team to focus on objective rather than subjective information, there is an elevated risk directly related to making group decisions in a limited social context (Schermerhorn, 2005, p. 232). Risks associated with effective decision-making in globally, outsourced virtual project environments are most productively mitigated via video-conferencing, group decision support tools (e.g. electronic meeting system) and establishment of team trust, knowledge management, and shared understanding.

\section{LIMITATIONS \& IMPLICATIONS FOR RESEARCH}

Limitations for this research included insufficient time and resources to perform an actual field study such as interviews, surveys or case studies to support from first-hand experience the framework that resulted from the literature review and synthesis of the existing research. Currently, the research provides great information on globally outsourced IT projects, but fails to present a comprehensive review of collaborative tools along with traditional project management methodology, e.g., contract management and effective team culture that facilitate the success of these projects. Future research should consider performance indicators while presenting the framework for virtual project management in relation to technology, project management methodology and effective virtual culture in undertaking a globally outsourced IT project. Most significantly, project performance related to project scope, cost and schedule should be captured and measured in future case studies, quantitative and qualitative research. In addition a research candidate profile for outsourcers and IT vendors should be created to assist future researchers in identifying the population of study.

\section{IMPLICATIONS FOR MANAGEMENT}

Fundamentally, key takeaways for managers of globally outsourced IT projects are that they require technology mediated communication, collaboration and an established project management methodology that encompasses an ability to manage project risk. There are several lessons learned for managers that emerge. First, there is a need to align project strategy with the overall strategy of the managing organization. Secondly, project managers need to create an environment conducive to high performance by using their people skills along with their technical skills in areas such as scheduling, procurement, cost estimating and budgeting, monitoring and controlling, and risk management in the virtual realm. Third, the virtual project environment is rapidly becoming the norm of global projects and will only become more prevalent in the very near future. Fourth, risks associated with establishing team trust in globally, outsourced virtual project environments is most effectively mitigated via a twopronged approach; leveraging collaborative technologies and face-to-face interactions. Fifth, risks associated with effectively managing knowledge and ensuring shared understanding in globally, outsourced virtual project environments are most successfully mitigated via an integrated framework that is appreciative of the dynamism of the people, efficiency of the processes utilized, and the value-add of the technology that supports the model. Lastly, risks associated with effective decision-making in globally, outsourced virtual project environments are most productively mitigated via video-conferencing, group decision support tools (e.g. electronic meeting system) and establishment of team trust, knowledge management, and shared understanding.

\section{CONCLUSION}

The historical, current and future expectations of the field of globally outsourced IT projects necessitate consideration of the proposed integrative project management framework coupled with collaborative tools and the establishment of an effective virtual culture for virtual project management. In essence, the paper's conclusion is limited in that there was no differentiation amongst the different types of IT projects such as hardware only, software only, or an enterprise endeavor. Moreover, there was no effort to address whether the globally outsourced projects were selective or total. Essentially, expansion of the literature is a significant implication that must be considered in the future. Since globally outsourced IT projects are inherently risky; when approaching virtual project management the actions to be taken require incorporation of the following: research framework, collaborative 
technology, the implications for managers, and the limitations of the conclusion. The method to utilize is employment of risk management techniques to reveal areas that do not conform to the aforementioned actions.

\section{Figures/Illustrations Are Available From The Authors Upon Request}

\section{REFERENCES}

1. Anonymous. (August, 2005). Application Compatibility Feature Team Guide: Overview of Application Compatibility. Retrieved July 6, 2008 from http://www.microsoft.com/library/media/1033/technet/images/desktopdeployment/bdd/standard/appcom01 big.gif

2. $\quad$ Beranek, T. R. (2006). Global project management: Graduate course. M.S. dissertation, University of Maryland, College Park, United States -- Maryland. Retrieved July 6, 2008, from Dissertations \& Theses: Full Text database. (Publication No. AAT 1436365).

3. Bouley, J. (2006). Leading versus managing. PMI Network, 20(2), 21-24.

4. Brooks, N. (2006). Understanding IT outsourcing and its potential effects on IT workers and their environment. The Journal of Computer Information Systems, 46(4), 46-53. Retrieved June 7, 2008, from ABI/INFORM Global database.

5. Chakrabarty, S., Whitten, D., \& Green, K. (2007). Understanding service quality and relationship quality in is outsourcing: Client orientation \& promotion, project management effectiveness, and the task-technologystructure fit. Journal of Computer Information Systems, 48(2), 1-15. Retrieved June 26, 2008, from Business Source Complete database.

6. Chen, Q., \& Lin, B. (1998). Global outsourcing and its managerial implications. Human Systems Management, 17(2), 109. Retrieved June 7, 2008, from Business Source Complete database.

7. Christian, P. (2002). New information technology accelerates delivery of major projects. Natural Gas (Wiley), p. 16-24. Retrieved July 26, 2008, from Business Source Complete database.

8. Cusick, J., \& Prasad, A. (2006). A practical management and engineering approach to offshore collaboration. IEEE Software, 23(5), 20-29. Retrieved June 7, 2008, from ABI/INFORM Global database.

9. $\quad$ Engleberg, I. \& Wynn, D. (2007). Working in groups: Communications principles and strategies ( $4^{\text {th }}$ ed.). Boston, MA: Houghton Mifflin Company.

10. Fraser, P., Farrukh, C., \& Gregory, M. (2003). Managing product development collaborations-a process maturity approach. Proceedings of the Institution of Mechanical Engineers -- Part B -- Engineering Manufacture, 217(11), 1499-1519. Retrieved June 10, 2008, from Business Source Premier database.

11. Gray, C. \& Larson, E. (2008). Project Management: The Managerial Process (4 ${ }^{\text {th }}$ ed). New York: McGraw Hill/Irwin.

12. Haddad, M. \& Ribière, V. (2007). The use of knowledge management in software acquisition. VINE, 37(3), 295-313. Retrieved June 20, 2008, from ABI/INFORM Global database.

13. Hambley, L., O'Neill, T., \& Kline, T. (2007). Virtual team leadership: Perspectives from the field. International Journal of E-Collaboration, 3(1), 40-64. Retrieved June 7, 2008, from ABI/INFORM Global database.

14. Kliem, R. (2004). Managing the risks of offshore IT development projects. Information Systems Management, 21(3), 22-27. Retrieved June 20, 2008, from ABI/INFORM Global database.

15. Murray, M. \& Crandall, R. (2006). IT offshore outsourcing requires a project management approach. S.A.M. Advanced Management Journal, 71(1), 4-11. Retrieved June 7, 2008, from ABI/INFORM Global database.

16. Pearlson, K. E., \& Saunders, C.S. (May, 2001). There's no place like home: Managing telecommuting paradoxes. The Academy of Management Executives, 117-128.

17. Project Management Institute (2004). A Guide to the Project Management Body of Knowledge Third Edition. Newtown Square, PA: Project Management Institute, Inc.

18. Qureshi, S., Liu, M., \& Vogel, D. (2006). The effects of electronic collaboration in distributed project management. Group Decision and Negotiation, 15(1), 55-75. Retrieved June 26, 2008, from ABI/INFORM Global database. 
19. Ranganathan, C., \& Balaji, S. (2007). Critical capabilities for offshore outsourcing of information systems. MIS Quarterly Executive, 6(3), 147-164. Retrieved June 10, 2008, from Business Source Complete database.

20. Schermerhorn, J. R., Hunt, J. G., \& Osborn, R. N. (2005). Organizational Behavior Ninth Edition. Hoboken, NJ: John Wiley \& Sons, Inc.

21. Taylor, H. (2006, November). Critical risks in outsourced it projects: The intractable and the unforeseen. Communications of the ACM, 49(11), 75-79. Retrieved July 19, 2008, from Business Source Complete database.

22. Thomas, D., Bostrom, R., \& Gouge, M. (2007). Making knowledge work in virtual teams. Communications of the ACM, 50(11), 85-90. Retrieved July 26, 2008, from Business Source Complete database.

23. Tiwana, A., \& Keil, M. (2004, November). The one minute risk assessment tool. Communications of the ACM, 47(11), 73-77. Retrieved July 19, 2008, from Business Source Complete database.

24. Workman, M. (2007). The effects from technology-mediated interaction and openness in virtual team performance measures. Behaviour \& Information Technology, 26(5), 355-365.

25. Xu, L. (2007). Outsourcing and multi-party business collaborations modeling. Journal of Electronic Commerce in Organizations, 5(2), 77-92, 94-96. Retrieved June 20, 2008, from ABI/INFORM Global database. 


\section{NOTES}

